\title{
Teach Multivariable Functions Through Applications and GeoGebra
}

\section{Maria Antonietta Lepellere}

University of Udine, Italy.

\begin{abstract}
In this paper some representative examples of a project proposed to second year environment and civil engineering students are presented. The project aim was to deepen the understanding of multivariable functions, stimulating students' creativity and connecting concepts to the content of other disciplines and to the real-world situations through examples that the students themselves have found as applications to engineering. To visualize the problems, students had often utilized GeoGebra, tool widely used during lectures to visualize theoretical aspects and to better explain the exercises. The appreciation of students involved in this activity and their relationship with GeoGebra is also presented. Students appreciated very much this approach as highlighted analyzing their written reports about the activity and GeoGebra use.
\end{abstract}

Keywords: Calculus; multivariable functions; GeoGebra; engineering applications. 


\section{Introduction}

Multivariable calculus is one of the most important parts of mathematics syllabus for engineering students. It is offered as a prerequisite course to other courses. However, multivariable calculus is one of the most difficult courses for most engineering students to study in their field. Various problematic areas have been identified, as the difficulty in coordinating procedures and manipulating concepts, poor problem-solving skills, the inability to select and use appropriate mathematical representations, the translation of realworld problems into calculus formulations, absorbing complex new ideas in a limited time, the students' beliefs, and their learning styles (Kashefi et al. 2011).

Faculties whose students need to use mathematics in learning their disciplines recommend mathematics classes to be made more relevant to their students (Abramovich \& Grinshpan, 2008). Engineering faculty have indicated that an engineering perspective may improve both students' motivation for learning mathematics and students' ability to transfer their mathematics learning to engineering contexts (Czocher, 2010; Pennell, Avitabile \& White, 2009; Varsavsky 1995). One of the problems in the early years in an engineering curriculum is that mathematics is taught as a separate subject. Moreover, it is beneficial for students to acquire practical experiences with real-world relevance too. Planning a course should not underestimate the three levels that influence students' behavior: the cognitive level, which concerns the learning of specific concepts and methods discipline; the meta-cognitive level, which concerns the control of subjects on their learning processes; and finally, the affective or non-cognitive level, which considers the beliefs, emotions, and attitudes of the learner (Zan et al. 2006). "Technology can play a role in each of these levels, including the noncognitive one, as it can deeply influence the beliefs, emotions and attitudes of learners, on the other hand, it is itself subject to rooted convictions and can provoke strong emotions" (Albano \& Ferrari 2008).

The use of information technologies and systems of dynamic geometry makes it possible to include a wide visual range in the educational process, thereby activating the imaginative thinking of students and helping them to holistically perceive the proposed material. The use of information technology allows the teacher to manage the demonstration of visual material more effectively. Mathematical concepts are identified and represented through various representations, which reflect possibly different features of a concept, but simultaneously complement each other. Treating a concept within a certain representation (representational mode or register) and successfully converting between different registers of representation, is considered as a prerequisite for conceptual understanding. Teaching GeoGebra, support multiple representations that can simultaneously demonstrate a function in numeric, algebraic, and graphic models. This feature helps students to understand abstract concepts, Nobre et al. 2016, Ponce Campuzano, et.al. 2018, Takaci et. al. (2015), and Tatar and Zengin 2016 explored students' learning outcomes in classes that applied GeoGebra to the teaching 
of calculus (see also Alessio et al.). GeoGebra supplemented lessons also enhanced students' motivation (Liu et al., 2011; Reis, 2010; Reis \& Ozdemir, 2010; Vargas \& Gamboa, 2013) and their mathematical reasoning and problem-solving skills (Acuña, 2014; Akanmu, 2016; Albaladejo et al., 2015; Granberg \& Olsson, 2015; Muzdalipah \& Yulianto, 2015).

The aim of this research is manifold, to investigate: the ability of students to connect their knowledge acquired in other courses (physics or engineering) where multivariable functions are used; the ability to transfer the same knowledge to real problems; the ability to use GeoGebra to represent a problem involving multivariable differential calculus and solve it; if the proposed work has found the interest of the students.

\section{Methodology}

The course of Mathematical Analysis 2 is a second course of calculus ( 9 credits corresponding to 72 hours of lessons) held in the first semester to second year students of Environment and Civil Engineering. It is preceded, among others, by Mathematical Analysis 1 (12 credits), Linear Algebra (6 credits) and Physics 1 (6 credits), it is simultaneously taught with Topography and Rational Mechanics. Mathematical Analysis 2 includes topics (in the order chosen for the lessons) as first and second order differentials equations, curves and curvilinear integrals, differential and integral calculus in several variables, vector calculus, the systems of linear differential equations with simple studies of stableness and Fourier series. Many students end up preparing the exam in mathematical analysis 2 in the third year after having successfully passed mathematical analysis 1 and linear algebra exams, slowing down their educational path. GeoGebra has intensively used to explain the properties of graphs of functions of several variables, the domain, the range, level curve or surface, the intersection of solid figures, the contours, and so on.

As optional additional work, assigning 3 extra bonus points for it, students were asked to find possible applications of the material studied to engineering and to present them to the class during the lessons. This work involves about eighty civil and environmental engineering students from the University of Udine, a town in the north-east of Italy. Most of them enrolled in the second year of studies but also third year or off-course students, who have not yet passed Mathematical Analysis 2 exam. Moreover, to students who participated in the project were also asked to make an optional report about their impressions of the work done and about GeoGebra. The request was the following: "write a report on your experience in preparing the proposed work on the engineering applications of the topics covered in class. If and how it helped you in understanding the theoretical topics and in connecting them with those of other courses. Explain if and how using GeoGebra helped you understand the course topics". 


\section{Results: The projects and the impressions}

Twenty-five students, out of eighty, prepared and presented their project during the lessons. Some of those related to other courses such as Rational Mechanics and Topography. Among twenty-five projects prepared by students, in this article, we have chosen to present three, about multivariable differential calculus. The choice was made to highlight some of the main advantages of using this activity that was the purpose of this work: finding links with the courses that students are following or followed in the past, or alternatively topics covered during high school; trying to model real problems using mathematical representations; acquiring some skills to solve a problem that could arise in the workplace. Here we also present some significant passages of the impressions, contained in the reports, about the project and their use of GeoGebra of the three students previously chosen.

\subsection{Isabel: An application in topographic field}

The objective Isabel work was the study of the environment and its conformation with an alternative (perhaps hypothetical) mathematical method that simplifies the topographic operations usually used to mimics the terrain. She also obtained a Plano-altimetric representation (through the level curves) and the maximum and minimum data of the territorial reliefs.
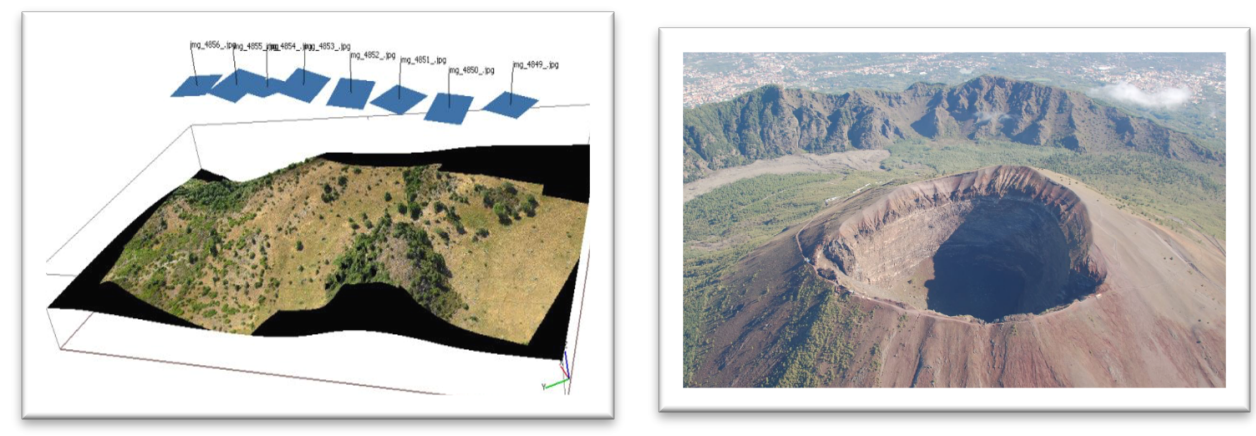

Figure 1. Environment conformation and Topographic method.

Among the functions chosen by Isabel there were:

$$
f(x, y)=\sin (x) \cos (y) \quad f(x, y)=\sin \left(\sqrt{x^{2}+y^{2}}\right)+1
$$



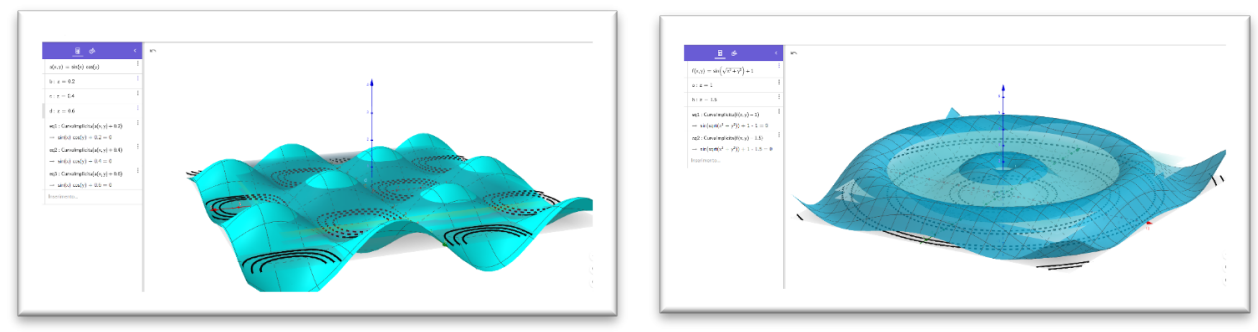

Figure 2. Two examples of functions chosen ad level curves with GeoGebra.

Through the graph of the functions and the level curves $f(x, y)=c$ (Figure 2.), she directly obtained the Plano altimetric representation of the territory on the $x y$ plane. She found the tangent plane of the function and maxima and minimum points. Students are not always able to connect the topics they encounter in other courses, sometimes the simple use of a different language confuses them, it is therefore necessary to show these links, and if they are the students themselves who find understanding, then it is even more effective.

About the impression of the project Isabel emphasizes the usefulness of the project to find links with other disciplines, in fact she wrote: "I found the project an excellent idea to make the students more interested in the subject, as a stimulus to look for something to propose and commit them to find real connections between the course and a wider context. I believe that, if you have found an interesting idea (but it is not easy) it can be a job to be developed later, with skills acquired in other courses". She also enjoyed using GeoGebra, in fact she said: "I had never used GeoGebra before, but it was very useful, I would like to learn the methods of representation using GeoGebra in more complex cases too".

\subsection{Gioele: Models of multivariable functions in some elements of historic buildings. Domes and Arch}

The domes of ancient churches are a demonstration of multivariable functions application. An example can be identified in the "basilica di Sant'Antonio di Padova (1310)", one of the main places of worship in Veneto. The Arch of Constantine (315), a triumphal arch located in Rome, is another example. Figure 3 illustrates the choices that Gioele made to select the functions and how he chose to display them using GeoGebra. 


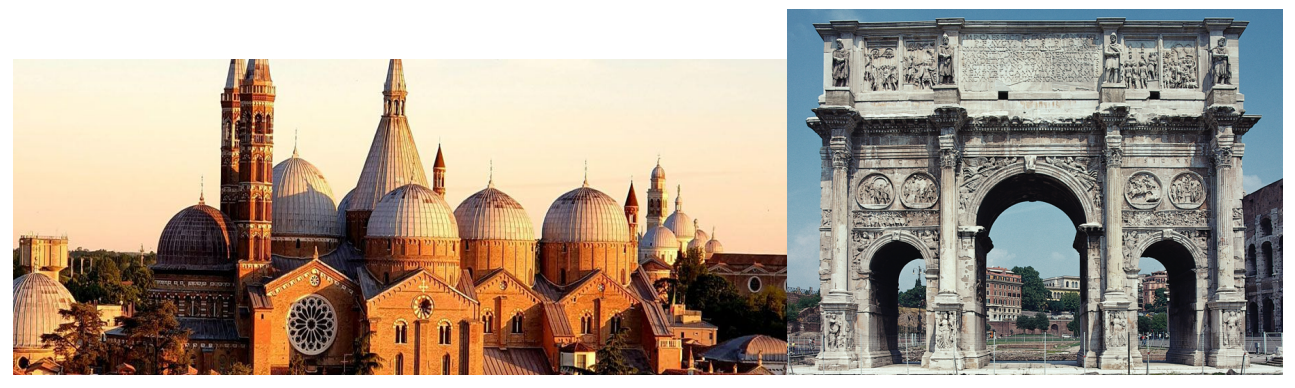

$\mathrm{a}=\operatorname{Superficie}\left(\mathrm{c}, 180^{\circ}\right.$, asseX)

$\rightarrow\left(\begin{array}{c}\cos (u) \cdot 3 \\ (\sin (u) \cdot 3) \cos (v) \\ (\sin (u) \cdot 3) \sin (v)\end{array}\right)$
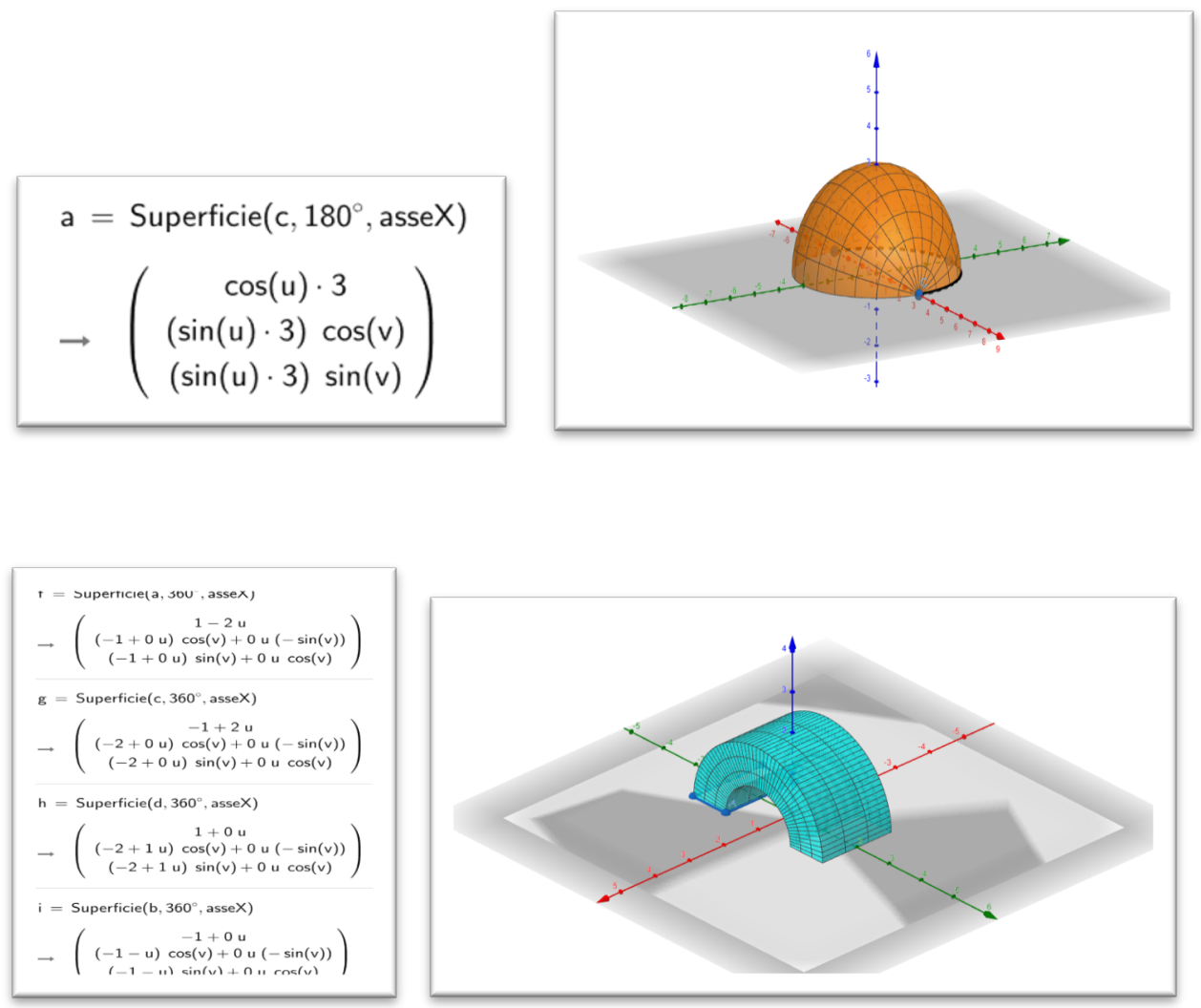

Figure 3. Domes and Arch.

Having introduced at the same time all the types of functions (of several variables, curves, surfaces) covered by the course allowed Gioele to obtain a representation very close to reality. In fact, after having chosen as the representation of a dome, the function $f(x, y)=$ $-\frac{x^{2}}{a}-\frac{y^{2}}{b}+c$, his attention immediately shifted towards the use of the rotation surfaces of curves. 
Unlike the other two, Gioele is a third-year student who felt the need to follow again the course since the teacher changed, previously the course was carried out in the traditional way. In fact, he wrote: "I was really pleased to follow again the analysis course 2 with this kind of approach since it was very useful not only for understanding this subject but also for deepening the comprehension of other courses" and he continued writing: "I found the teaching activity related to mathematical applications in the engineering field stimulating and allowed me to have a broader overview of my future profession. Sometimes in some degree courses there is no correlation between the theory that is learned and the consequent use from a practical point of view. Having carried out an activity of this type has also allowed me to find, through reasoning, alternatives to the problems that may arise during my professional activity". Gioele's desire to connect the topics dealt with the future working reality is therefore evident. About GeoGebra he wrote: "I believe that the use of GeoGebra has been of great help as regards the intermediate phase between learning and applications; thanks to a graphic vision, I believe that the acquisition of theoretical arguments is very simplified, allowing a first physical vision of the problem too". He also highlighted the importance of the tool to understand more deeply the theoretical contents of the course. He continues writing for the general approach used: "The study of certain concepts in this way has allowed an easier understanding of the same topics seen in other courses allowing a significant simplification of the learning phase. I find this type of approach very useful, especially in mathematics subjects because I personally believe that many concepts are delicate to understand and noting concrete results you have further help".

\subsection{Thomas: Calculate the dimensions of the ideal cut section for a tree trunk}

The shape of a trunk is irregular, as the various cross sections; he therefore wanted to determine what are the dimensions of the rectangle, with vertices belonging to the "tangent" circumference that maximize the resistance modulus $W=\frac{1}{6} b h^{2}$ (see Figure 4).

The set of pairs $(b, h)$ of the first quadrant representing the rectangles inscribed on the circumference of diameter $d$ are precisely the pairs that are located at a distance $d$ that belonging to $D=\left\{(b, h) \mid b^{2}+h^{2}=d^{2}, b \geq 0, h \geq 0\right\}$.

Using the Lagrange multiplier theorem, Thomas found the maximum point $\left(\frac{d}{\sqrt{3}}, \sqrt{\frac{2}{3}} d\right)$. 


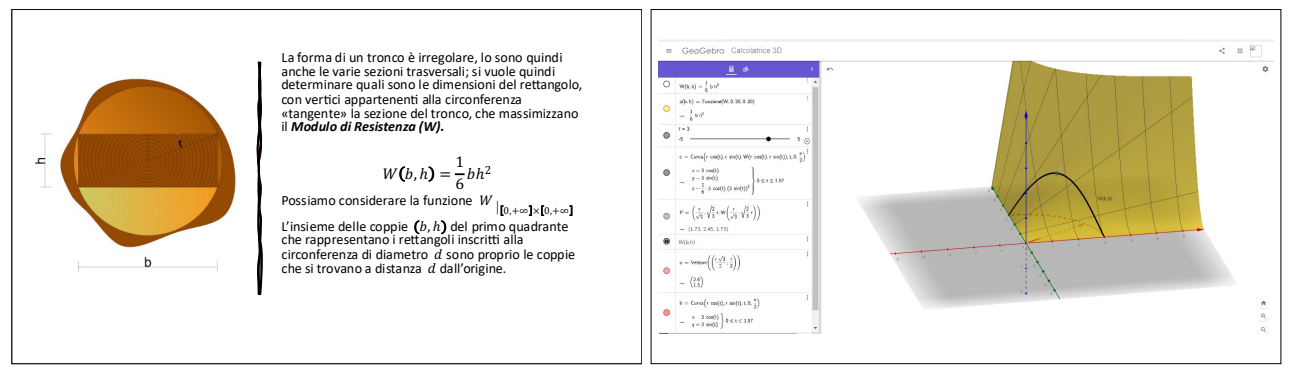

Figure 4. The problem. The graphical interpretation and the solution.

In this case, Thomas' ability to model the problem and solve it both analytically and geometrically with GeoGebra is highlighted. He was capable to relate the three-dimensional representation, in particular the curve identified by the substitution of the constraint, with its projection on the $x y$ plane. It is important to note the choice of the slider to show how the maximum is obtained. About the impressions of the project, he wrote: "Having performed this exercise helped me to understand how to display functions in multiple variables, in fact I had never thought that the modulus of resistance function could be displayed as a function of two variables". Having to look for examples of functions of several variables forced Thomas to reflect on what the various possibilities could be, in fact at first time he presented a similar example but for functions of one variable. The transition from functions of one to several variables is in fact recognized as an epistemological obstacle. About GeoGebra he wrote: "The use of Geogebra was very useful for the graphical display of functions in two variables, curves and vector fields, but in general of all the functions that can be viewed in a three-dimensional space. Carrying out exercises, example accompanied by images created with GeoGebra seemed to me an excellent approach to clarify analytical concepts through geometric interpretations. It was also helpful to integrate the theoretical slides with figures created using GeoGebra".

\section{Conclusions}

Students' beliefs about the relevance of mathematics are considered as one of the factors that can play an important role in their attitude and motivation. A recent study of first year university students in engineering focused on improving perceptions of the relevance of mathematics in engineering, Flegg (2012) has described the use of context-based learning by applying mathematics to real-life problems as a promising approach.

The transfer of mathematics into the context of engineering seems difficult. Therefore this paper proposes a project that involves the students firsthand in order to incorporate mathematics with the principles of engineering. 
The experience with the students was very encouraging. Both second-year, third-year and off-course students benefited from the initiative. The first because they had to reflect on the true meaning of the new concepts in order to find possible applications, connect the topics just learned with those they were taught at the same time in other disciplines, they also became aware of further applications that they will encounter in subsequent courses such as Construction Science and Hydraulics or in the workplace. For third-year or off-course students it was used to recognize mathematical concepts seen in other engineering courses. For everyone, preparing and presenting a project to the whole class served to test their exhibition skills too. The activity was highly appreciated by the students as evidenced by the words of the students themselves. The use of GeoGebra was very useful both to understand the concepts and examples shown during the lessons but also a valid tool that accompanied the students in the individual solving of the exercises. It is interesting that they were the students themselves who chose how to apply the tool in their project. The fact of them choosing it according to their personal interest and applying it and seeing the professional utility is a change with respect to the obligation to perform a task already predefined by the teacher.

The experience with the students was very positive and encourages its use in the coming years as well.

\section{References}

Abramovich, S. \& Grinshpan, A. (2008). Teaching mathematics to non-mathematics majors through applications, PRIMUS: Problems, Resources, and Issues in Mathematics Undergraduate Studies, 18 (5), 411-428.

Albano G., Ferrari P.L. (2008). Integrating technology and research in mathematics education: the case of e-learning. In: Garcia Penalvo, F.J. (ed.) Advances in E-learning: Experiences and Methodologies, 132-148. Information Science Reference (IGI Global), Hershey (PA-USA).

Alessio, F., Demeio, L., and Telloni, A.I. (in press). A formative path in tertiary education through Geogebra supporting the students' earning assessment and awareness, International Journal of Technology in Mathematics Education.

Czocher, J. (2010). An exploration of factors that influence student achievement in differential equations, Columbus, $\mathrm{OH}$ : Poster presented at the $32 \mathrm{nd}$ annual meeting of the North American chapter of the Psychology of Mathematics Education group.

Duval D. (1999). Representation, vision and visualization: Cognitive functions in mathematical thinking. Basic issues for Learning (Plenary address). In F. Hitt and M. Santos (Eds), Proc. 21st PME-NA Conference, 1 (pp. 3-26). Cuernavaca, Morelos, Mexico.

Flegg, J., Mallet, D., \& Lupton, M. (2011). Students' perceptions of the relevance of mathematics in engineering. International Journal of Mathematical Education in Science and Technology, 1-12. 
Lepellere M.A., Cristea I., Gubiani I. (2019). The E-learning system for teaching bridging mathematics course to applied degree studies, In: Flaut C., 591 Hoškovà-Mayerovà Š., Flaut D. (eds), Models and Theories in Social Systems. Studies in Systems, Decision and Control, 179, Springer, Cham, 295-309.

Lepellere, M.A., Urbinati, S., Salahi Al Asbahi, N. (2020). Teaching Multivariable Differential Calculus using Geogebra and Quizzes, INTED2020 Proceedings, pp. 90539058.

Nobre, C. N., Meireles, M. R. G., JUNIOR, N. V., Resende, M. N.d., Costa, L. E.d., \& Rocha, R. C.d. (2016). The use of geogebra software as a calculus teaching and learning tool. Informatics in Education, 15(2), 253-267.

Kashefi, H. ,Zaleha Ismail.,Yudariah Mohd Yusof. (2011). Students' Difficulties in Multivariable Calculus Through Mathematical Thinking Approach, Journal of Edupres, 1, 77-86.

Pennell, S., Avitabile, P., \& White, J. (2009). An engineering-oriented approach to the introductory differential equations course. PRIMUS: Problems, Resources, and Issues in Mathematics Undergraduate Studies, 19(1). 88-99.

Ponce Campuzano, J. C., Matthews, K. E., \& Adams, P. (2018). On the use of history of mathematics: An introduction to galileo's study of free fall motion. International Journal of Mathematical Education in Science \& Technology, 49(4), 517-529.

Tall D.O. (2003). Using Technology to Support an Embodied Approach to Learning Concepts in Mathematics, First Coloquio de Historia e Tecnologia no Ensino de Matemática, at Universidade do Estado do Rio De Janeiro, February 21-3, 2002,1-28.

Tall D.O. (2004). Thinking Through Three Worlds of Mathematics. Proceedings of the 28th Conference of the International Group for the Psychology of Mathematics Education, Bergen, Norway, 4, 281-288.

Tall D.O. (2007). Embodiment, Symbolism and Formalism in Undergraduate Mathematics Education, Plenary at 10th Conference of the Special Interest Group of the Mathematical Association of America on Research in Undergraduate Mathematics Education, Feb 2227, San Diego, California, USA.

Takaci, D., Stankov, G., \& Milanovic, I. (2015). Efficiency of learning environment using GeoGebra when calculus contents are learned in collaborative groups. Computers \& Education, 82, 421-431.

Tatar, E., \& Zengin, Y. (2016). Conceptual understanding of definite integral with GeoGebra. Computers in the Schools, 33(2), 120-132.

Varsavsky, C. (1995). The design of the mathematics curriculum for engineers: A joint venture of the mathematics department and the engineering faculty. European Journal of Engineering Education, 20(3), 341-345.

Zan, R., Brown, L., Evans, J. \& Hannula, M. (2006). Affect in mathematics education: an introduction. Educational Studies in Mathematics, Special Issue, 63 (2), 113-121. 